\title{
How High Involvement Work Systems Influence R\&D Professional's Innovative Performance: An Analysis of the Mediated Moderation Effect

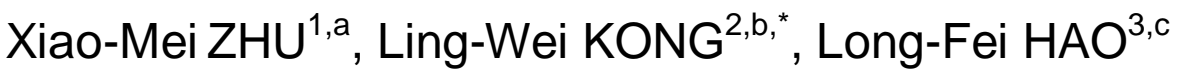 \\ ${ }^{1,2,3}$ School of Economics and Management, East China Jiaotong University, Nanchang, P. R. China, 330013 \\ axiaomeizhu99@163.com, bsushouyanmo@126.com, c1154943195@qq.com \\ ${ }^{*}$ Corresponding author
}

Keywords: High involvement work systems, Consciousness, Trust in supervisor, Innovative performance.

\begin{abstract}
In this study, a mediated moderation model has been constructed based on $356 \mathrm{R} \& \mathrm{D}$ professionals' survey to explain the influence of high involvement work systems on professional's innovative performance. The results show that: (1) high involvement work systems have significantly positive effect on professional's innovative performance; (2) consciousness moderates the effect of high involvement work systems on professional's innovative performance; (3) supervisor trust mediates the moderating effect of consciousness between high involvement work systems and professional's innovative performance.
\end{abstract}

\section{Introduction}

HIWSs refer to a group of human resource (HR) practices, and have received significant attention among scholars. The relationship between HIWSs and employee's attitudes and behaviors has been proved by an amount of empirical research [1]. However, most of the researches of HIWSs are aimed at manufacturing industry, and there have been few studies to select high tech industry's employees as subjects investigated.

R\&D professional's innovation is crucial to high tech enterprise's survival and development. So how to improve professional's innovative performance has become the urgent question to be solved. In past research, human resource management has been highlighted as one of the most influential factors in a firm's innovative behaviors [2]. Therefore, in this study, we try to test whether HIWSs affect $R \& D$ professional's innovative performance.

In the Big Five personality model, consciousness has been considered to have significant impact on employee's job performance [3]. That is to say, in the same work environment, individuals with different levels of consciousness may show different job performance. In addition, the effects of trust in supervisor on employee's attitudes and behaviors have attracted the attention of some scholars [4]. Therefore, we introduced consciousness and trust in supervisor, trying to explore their effects on the relationship between HIWSs and R\&D professional's innovative performance.

\section{Literature review}

\section{HIWSs and innovative performance}

HIWSs refer to a group of separate but interconnected human resource (HR) practices, including rigorous and selective staffing, extensive training and development, incentive compensation, and merit-based performance appraisal. Although a large number of empirical studies have tested the relationship between HIWSs and employee's attitudes and behaviors [1], there are few study emploring the relationship between HIWSs and employees' innovative performance.

HIWSs have great influence on employee's mentalities, attitudes, behaviors and abilities, which in turn affect employee's creativity [5]. Studies have showed that creativity has significant effect on innovative performance [6]. Furthermore, HIWSs give employees more autonomy and greater job diversity [7]. In this environment, employees have more opportunities to capture different 
knowledge, which will make them produce more innovative performance [8]. In conclusion, we hypothesize that:

Hypothesis 1 High involvement work systems will be positively related to professional's innovative performance.

\section{The interaction effect of HIWSs and consciousness}

Consciousness is an important characteristic of one's mentality, reflecting a person's conscious attitudes towards group's common activities, code of conduct, and his tasks. Some scholars have found that consciousness has positive effect on individual's performance [3].

According to the theory of person-environment fit, a good fit of the individual and the environment has positive effect on one's behavior [9]. Employees with high consciousness have strong planning and self-control abilities, as well as desires to success [10], so they have high creativity [11] and can work actively [12]. Furthermore, they disgust restrictions of rules [13]. Therefore, the fit between professionals with high consciousness and HIWSs is good. In the relaxed working environment of HIWSs, professionals with high consciousness can carry out more innovative performance. Above all, we hypothesize that:

Hypothesis 2 There is an interaction effect between high involvement work systems and consciousness on professional's innovative performance.

\section{HIWSs, consciousness, trust and innovative performance.}

Trust in supervisor, refers to a kind of mentality that employees have active, positive and good expectations for the supervisor and are willing to accept his various acts [14]. Studies showed that the management practices of the organization have positive effect on employee's trust to supervisor [15]. And some scholars have examined that trust in supervisor significantly influences employee's work attitudes and performance [4]. Zhang and Xia (2011) particularly pointed that employee's trust has obviously impact on innovative performance [16]. Thus, as a group of separate but interconnected human resource (HR) practices, HIWSs may have positive effect on professional's innovative performance through creating their trust to the supervisor. Moreover, as a result of the good fit between professionals with high consciousness and HIWSs, high consciousness professionals are more likely to be affected by HIWSs and then show more innovative performance. In conclusion, we hypothesize that:

Hypothesis 3 The interaction effect of high involvement work systems and consciousness on professional's innovative performance will be mediated by trust in supervisor.

\section{Method}

\section{Participants}

The sample was composed of 356 full-time R\&D professionals from 20 enterprises. Of the respondents, $28.7 \%$ were women and $71.3 \%$ were men; $65.2 \%$ were $20-29$ years old, $27.2 \%$ were 30-39 years old, 5.6\% were 40-49 years old, and $2 \%$ were aged 50 or over. The education level of the respondents varied: $7.6 \%$ had some college training, $47.2 \%$ had a bachelor's degree, $37.6 \%$ had a graduate degree, and $7.6 \%$ had a doctoral degree. The respondents' average years of work experience were as follows: 0-1 year (19.1\%), 1-3 years $(22.2 \%), 3-5$ years $(30.1 \%), 5-10$ years $(16.0 \%)$, and over10 years $(12.6 \%)$.

\section{Measures}

High involvement work systems (HIWSs). High involvement work systems were measured using the fifteen-item scale provided by Xiao \& Björkman(2006)[17], a sample item is "Careful selection procedures in recruiting (careful selection)". All responses were made on a five-point Likert scale ranging from 1 (strongly disagree) to 5 (strongly agree). The Cronbach's alpha for this scale was 0.856 .

Consciousness(C). Consciousness was assessed with ten-item scale adapted from Mlačić Goldberg (2007) [18], four of which are negative scoring. For example, "I'm always ready", "I pay 
attention to details". The scale uses a five-point Likert response anchored by $1=$ strongly disagree and $5=$ strongly agree. The Cronbach's alpha for this scale was 0.807 .

Trust in supervisor (TS). Trust in supervior was measured by four items developed by Farh, Tsui, Xin \& Chen (1998) [19], a sample item is "I have complete faith in the integrity of my supervisor". All items were measured on a five-point Likert scale from 1 (strongly disagree) to5 (strongly agree). The Cronbach's alpha for this scale was 0.701 .

Innovative performance (IP). Innovative performance was measured using a eight-item scale developed by Han, Liao \& Long (2007)[20]. For example, "actively support the new ideas". Responses to these items were made on a five-point Likert-type scale ranging from 1 (strongly disagree) to 5(strongly agree). The Cronbach's alpha for this scale was 0.731 .

Control variables. Individuals's gender, age, and organizational tenure were included as control variables in our analyses to rule out potential alternative explanations for our findings.

\section{Result}

\section{Descriptive statistics and correlation matrix}

A correlation matrix of all the variables is presented in Table1. The means, standard deviations, and alphas for scaled variables are reported in this table as well.

Table 1 Descriptive statistics, correlations for scale variables

\begin{tabular}{|c|c|c|c|c|c|c|}
\hline & $\mathrm{M}$ & $\mathrm{SD}$ & 1 & 2 & 3 & 4 \\
\hline 1.high involvement work system & 3.64 & 0.45 & 1 & & & \\
\hline 2. consciousness & 4.10 & 0.52 & $.520^{* *}$ & 1 & & \\
\hline 3. trust in supervisor & 4.03 & 0.61 & $.528^{* *}$ & $.475^{* *}$ & 1 & \\
\hline 4. innovative performance & 3.79 & 0.36 & $.384 * *$ & $.442^{* *}$ & $.540^{* *}$ & 1 \\
\hline
\end{tabular}

$* \mathrm{p}<0.05, * * \mathrm{p}<0.01$

\section{Regression results}

To test a main effect of HIWSs on innovative performance (Hypothesis 1), we first loaded control variables in step 1 (Model 1). Then, we added HIWSs in the regression (Model 2). The results indicate that HIWSs had a significant positive relationship with innovative performance $(\beta=.414, \mathrm{p}<0.01)$. Hypotheses 1 was fully supported.

To test an interaction effect between HIWSs and consciousness (Hypothesis 2), we added consciousness and an interaction term between HIWSs and consciousness in the regression (Model $3)$. In order to reduce any multicollinearity problem, the scores of HIWSs and consciousness were mean-centered [21]. The result shows that the interaction of HIWSs and consciousness had significant influence on innovative performance $\left(\beta=-.457^{* *}, \mathrm{p}<0.01\right)$. Thus, Hypothesis 2 was supported. We plotted our interaction to aid in the interpretation of the moderator test results, as shown in Figure1.

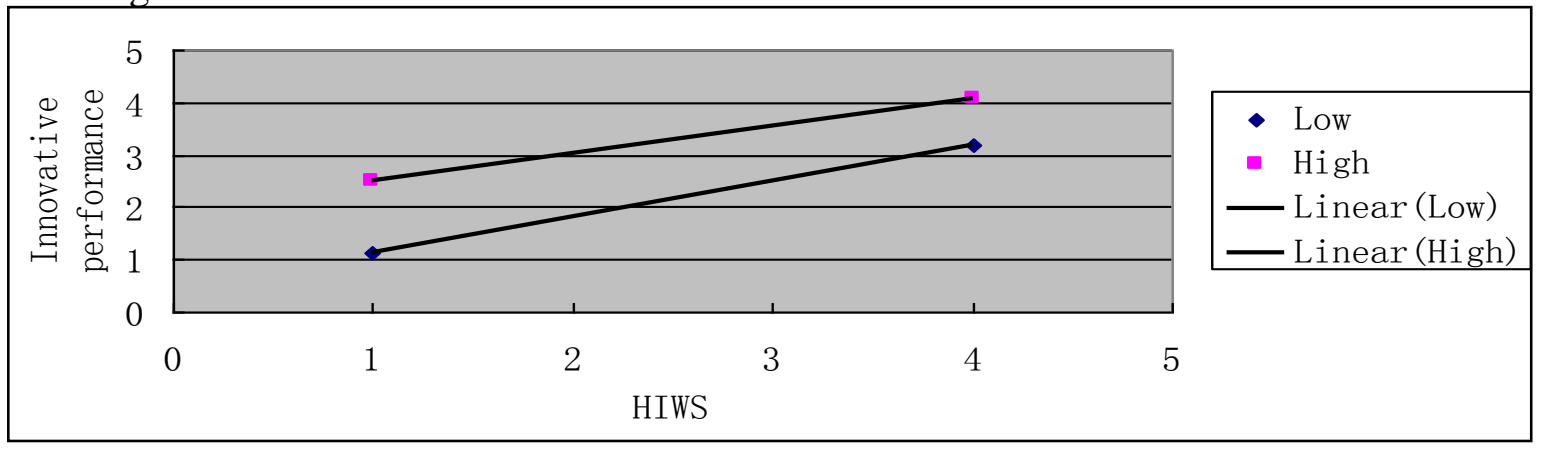

Figure 1 The interaction between HIWSs and consciousness on innovational performance 
To test Hypothesis 4, mediated moderation effects, we followed suggestions by Muller, Judd, and Yzerbyt[22]. The results of Model 4 show that the interaction of HIWSs and consciousness had significant effect on trust in supervisor. Then, we ran a hierarchical regression with innovative performance as the dependent variable, with the control variables and independent variables of HIWSs and consciousness and their interaction entered first, followed hierarchically by the mediator of trust in supervisor. The results in Table 2 (Model 5) shows that the mediator of trust in supervisor had positive significant effect on innovative performance, and the beta weight for interaction of HIWSs and consciousness was reduced from $-.457(\mathrm{p}<.01)$ to.$- .409 * *(\mathrm{p}<.01)$. Therefore, evidence of partial mediation exists and Hypothesis 3 was partially supported.

Table 2 Hierarchical Regression Results for Testing Mediated Moderation Effects

\begin{tabular}{|c|c|c|c|c|c|}
\hline \multirow[t]{2}{*}{ Variables } & \multicolumn{4}{|c|}{ Innovative performance } & \multirow{2}{*}{$\begin{array}{c}\text { Trust in } \\
\text { Supervisor } \\
\text { Model } 4\end{array}$} \\
\hline & Model 1 & Model 2 & Model 3 & Model5 & \\
\hline Gender & $-.111 *$ & -.080 & -.035 & -.032 & .017 \\
\hline Age & .002 & .082 & .032 & .073 & -.115 \\
\hline Education & -.091 & $-.168 * *$ & -.065 & -.072 & .011 \\
\hline Tenure & -.066 & $-.137 *$ & .020 & -.082 & $.298 * *$ \\
\hline HIWSs & & $.414 * *$ & $.148 * *$ & .037 & $.284 * *$ \\
\hline Consciousness & & & & & $.273 * *$ \\
\hline HIWSs $\times$ Consciousness & & & $-.457 * *$ & $-.409 * *$ & $-.187 * *$ \\
\hline Trust in supervisor & & & & $.363 * *$ & \\
\hline $\mathrm{R}^{2}$ & 0.025 & .188 & .420 & .501 & \\
\hline$\Delta \mathrm{R}^{2}$ & 0.025 & .163 & .233 & .081 & \\
\hline $\mathrm{F}$ & 2.249 & $16.169 * *$ & $36.057 * *$ & $43.538 * *$ & \\
\hline
\end{tabular}

$* \mathrm{p}<0.05, * * \mathrm{p}<0.01$

\section{Conclusion}

In conclusion, the paper demonstrates that HIWSs has significantly effect on R\&D professional's innovative peformance through creating their trust to the supervisor. Moreover, consciousness moderates the ralationship between HIWSs and innovative performance.

One thing needs to be pointed out. As Figure 1 shows, at the same level of HIWSs, professionals with high consciousness show higher innovative performance than the low consciousness professionals. This may be because the good fit of high consciousness professionals and HIWSs make high consciousness professionals easily create trust to the supervisor, and then show higher innovative performance. However, as the increasing of the perception level of HIWSs, the improvement range of the low consciousness professionals' innovative performance is high, compared to professionals with high consciousness. Maybe the following two points could explain this conclusion.

Firstly, HIWSs in this study was based on Chinese context, in which employment security are not seen as signs of an employer's commitment to its employees[17]. To deal with the employment insecurity, employees need to actively maintain and develop their own employability. This forces low consciousness professionals to work hardly to keep the job. Secondly, Employees with high consciousness have strong planning and self-control abilities, as well as desires to success[10], so without the conveniences provided by HIWSs, they can still work actively[12], that is to say, the environment has limited impact on high consciousness professionals. While low consciousness professionals are easily influenced by the environment. When the pressure of keeping the job forced them to work hardly, they may be easily affected by the various conveniences provided by HIWSs, then exhibit high innovative performance.

This study makes second contributions to HIWSs literature. First, we intend to integrate 
employee, supervisor and organization perspectives to examine the influence of HIWSs on professional's innovative performance, unveiling the black box of the relationship between HIWSs and employee performance. Second, we collect data from high-tech enterprises, extending extant HR research beyond focusing on manufacturing firms.

The conclusions of this study indicate that managers can improve employees' innovative performance by establishing easily intelligible HIWSs and they also point out some strategies to improve employees' innovative performance. That is, managers should consider the indirect effect of employees' consciousness and trust on performance. In addition, managers also should pay attention to employee's personalities, because different employees may have different responses to the same environment.

An important limitation of this study derives from our use of cross-sectional data. Future research should make use of longitudinal data from the organizational setting to test the causal order of the relationships established in the hypotheses.

\section{Acknowledgement}

This research was financially supported by the National Science Foundation (No. 71162006) and Fund of post-PhD (No. 2012M510853).

\section{References}

[1] S. Wang, X. Yi, J. Lawler, et al, Efficacy of high-performance work practices in Chinese companies, The International Journal of Human Resource Management. 11(2011)2419-2441.

[2] D. Jimenez-Jimenez, R. Sanz-Valle, Innovation and human resource management fit: an empirical study, International Journal of Manpower. 4(2005) 364-381.

[3] M.R. Barrick, M.K. Mount, The Big Five personality dimensions and job performance, Personnel Psychology. 44(1991)1-26.

[4] L. Wu, J. Liu, G. Liu, Abusive supervision and employee performance: mechanisms of traditionality and trust, Acta Psychologica Sinica. 6(2009)510-518.

[5] Y. Shi, N. Li, Review and prospect of international high-performance human resource practices, Management Review. 10(2011)83-90.

[6] T.M. Egan, Factors influencing individual creativity in the workplace: an examination of quantitative empirical research, Advances in Developing Human Resources. 2(2005)160-181.

[7] Y. Shi, N. Li, The review of high involvement work systems and firm performance, Science and Technology Management Research. 12(2009)264-267.

[8] U.R. Hulsheger, N. Anderson, and J.F. Salgado, Team-level predictors of innovation at work: a meta-analysis spanning three decades of research, Journal of Applied Psychology. 5(2009)1128-1145.

[9] J.R. Edwards, Person-environment fit in organizations: an assessment of theoretical progress, Academy of Management Annals. 8(2008)167-230.

[10] P.T. Costa, R.R. McCrae, The NEO personality inventory: manual form $S$ and form R, Psychological Assessment Resources. (1985)

[11] W. Fang, L. Wang, G. Feng, et al, Exploring the relationship of intrinsic motivation, leader emotional intelligence and employee creativity, Science \& Technology Progress and Policy. 7(2014)142-148.

[12] T.M. Amabile, Creativity in context, Boulder, CO: Westview Press, 1996.

[13] G.M. Spreitzer, Psychological empowerment in the workplace: dimensions, measurement and 
validation, Academy of Management Journal. 5(1995)1442-1465.

[14] H. Wei, L. Long, Effect of supervisor cognitive trust and emotional trust on employee behavior and performance, Acta Psychologica Sinica. 11(2009)86-94.

[15] S.S. Tzafrir, Y. Baruch, S.L. Dolan, The consequences of emerging HRM practices for employees' trust in their managers, Personnel Review. 6(2004)628-647.

[16] W. Zhang, H.S. Xia, Research on the relations of charismatic-typed leader, trust of subordinates and performance of team innovation, Science and Technology Management Research. 8(2011)109-112.

[17] Z. Xiao, I. Björkman, High commitment work systems in Chinese organizations: a preliminary measure, Management and Organization Review. 3(2006)403-422.

[18] B. Mlačić, L.R. Goldberg, An analysis of a cross-cultural personality inventory: the IPIP Big-Five factor markers in Croatia, Journal of Personality Assessment. 2(2007)168-177.

[19] J.L. Farh, A.S. Tsui, K. Xin, The influence of relational demography and guanxi: the Chinese case, Organization Science. 9(1998)471-488.

[20] Y. Han, J. Liao, L. Long, Model of development and empirical study on employee job performance construct, Journal of Management Sciences in China. 5(2007) 63-77.

[21] L.S. Aiken, S.G. West, Multiple regressions: testing and interpreting interactions, Newbury Park, CA: Sage, 1991.

[22] D. Muller, C.M. Judd, V.Y. Yzerbyt, When moderation is mediated and mediation is moderated, Journal of Personality and Social Psychology. 6(2005)852. 